\title{
Revisiting Translation Quality Assurance: A Comparative Analysis of Evaluation Principles between Student Translators and the Professional Trans-editor
}

\author{
Wan $\mathrm{Hu}^{1, *}$ \\ ${ }^{1}$ School of Foreign Studies, Central University of Finance and Economics, Beijing, China \\ *Correspondence: Wan Hu, 39 South College Road, Central University of Finance and Economics, Haidian District, \\ Beijing 100081, China. E-mail: huwan@cufe.edu.cn \\ This research was supported by the CUFE Research Management Office and the Teaching Research Project of \\ Central University of Finance and Economics [grant number 2018XYJG13].
}

Received: December 7, 2018

Accepted: December 19, 2018 Online Published: December 21, 2018

doi:10.5430/wje.v8n6p176

URL: https://doi.org/10.5430/wje.v8n6p176

\begin{abstract}
Evaluation is of paramount significance in the teaching and learning process. So is true with translation teaching and learning. This study uses in-depth interview to qualitatively examine in which ways the student translators and the professional trans-editor, two important stakeholders in the learning process, evaluate the work of translation. It then subsequently compares student translators' and the professional trans-editor's evaluation criteria in order to analyse the differences. This study also compares students' pitfalls encountered during the translation process, providing students with invaluable resources to reflect on their own translation and then to improve their translation quality. An implication of this study is that the interaction among students, professional trans-editor, and university lecturers may ultimately be beneficial to translator training.
\end{abstract}

Keywords: professional evaluation, peer evaluation, qualitative research, university-industry collaboration, news translation

\section{Introduction}

With the burgeoning development of translation courses in the West and China from undergraduate to PhD levels and due to the practical nature of translation, many scholars have discussed the possibilities of balancing academic teaching and professional needs in translation programmes (Kelly, 2005; Li, 2012; Hu, 2018) from the perspective of curriculum design, teaching methods, real or simulated translation projects, and internship places. However, few research projects have been carried out on the integration of academic and professional pedagogies from the perspective of translation quality evaluation. In addition, translation students' perceptions, an important component when looking at the translation learning process, have been examined to an even lesser degree.

This study on 'comparing student translators' peer evaluation and professional trans-editor's final corrections' was conceived in this context. With an aim of investigating "who evaluates and also how to evaluate the translation work", this paper combines the preliminary observations in the teaching of a core module about finance and economics news with in-depth interviews of student translators and the professional trans-editors. Based on the empirical data, this paper sums up the different translation evaluation principles in different contexts as well as student translators' common pitfalls during the translation processes, and analyses the rationales behind such phenomenon.

\section{Translation Quality Evaluation}

The evaluation of translation quality is an essential component in the translation teaching and learning process (Kelly, 2005; Colina, 2015), which is crucial to ensure whether translation learners have achieved their intended learning outcomes as well as to validate the effectiveness of the teaching syllabus. Many translation scholars have discussed quality issues from both theoretical considerations and practical applications. For example, House (1977; 1997; 2015) 
proposes two evaluation models of translation quality and applies these models in evaluating different types of translated texts (e.g. commercial texts; children's literature). To be more specific, in her original model, functions of language is emphasised, analysing "linguistic-discoursal as well as the situational-cultural particularities of originals and translated texts" (ibid., 2015, p.21). The revised House model, places more emphasis on functions of texts, analysing semantical and pragmatical equivalences between the source and target texts (ibid., p.63). In addition, House (2015, p.8-15) analytically reviews different approaches to evaluating translations in accordance with different purposes, functions and preferences. These approaches are: phyco-social approaches; response-based approaches; text and discourse-oriented approaches; linguistically oriented approaches, and some specific approaches including content-oriented approach, target text oriented approach, comprehensive textual analysis, as well as others.

Kelly (2005), compares functions of the traditional summative assessment methods (e.g. an unseen examination) and of the innovative formative assessment methods (e.g. a translation portfolio), from the perspective of translator training, arguing the importance of "making translation exams more realistic" (2005, p.136). In this sense, she also argues different stakeholders should be involved in the translation evaluation process. Apart from university teachers' marking and evaluations, translation learners and experienced practitioners from the translation profession may also be included in the evaluation, giving peer feedback and industry-based feedback on students' translation work.

Mossop (2010), based on his considerable experience of translation practice, presented a clear step-by-step guideline on the revising and editing of translation work, aiming to provide translation learners and professional translators with detailed criteria and principles for improving their self-revision ability or the ability to revise the work of others. Translators, taking these principles into consideration, are made aware of how many levels of content ought to be evaluated and how many factors should be included in the translation decision-making process. This helps to assure their translation quality.

With an aim of training professional translators, Orlando (2011) investigates different evaluation grids used by translation agencies, international organizations and government departments in order to help translation instructors form a more professional-based approach. However, considering the research-led teaching nature of university education, evaluating translation students' learning processes is also of paramount importance to improving outcomes. After examining both evaluation methods from the industry and students' academic knowledge, Orlando proposes two different evaluation grids which consist of translation product-oriented evaluation and translation process-oriented evaluation (2011, p.302-303). These two grids complement each other.

Colina (2015), in her recent book Fundamentals of Translation, clarifies two different objects of evaluation, namely evaluating student translations and professional translations. The former refers to the translation work produced in the educational context, while the latter deals with translations produced for professional use. More specifically, the evaluation in the educational context is designed to help students achieve learning objectives and to serve as the instructor's diagnostic tool. The evaluation in the professional context, however, may also assess whether the translation product meets market or industry standards, and can "contribute to professional development” (2015, p.224).

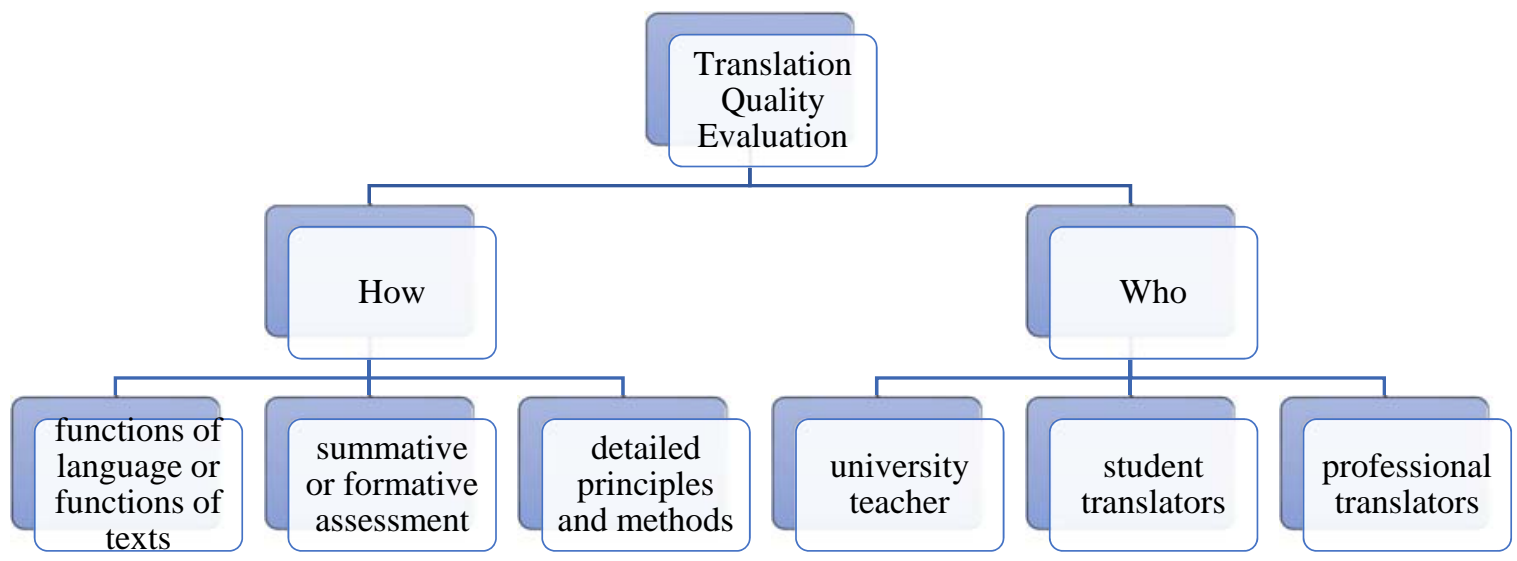

Figure 1. Translation Quality Evaluation: How to Evaluate and Who to Evaluate 
To sum up, as shown in Figure 1, the above literature on translation quality evaluation mainly focus on two dimensions: how to evaluate and who is evaluating? In answering the "how" question, evaluation approaches, frameworks and the ethos of embedding professional criteria into the evaluating process are mentioned. As regards the "who" question, university lecturers, translation students and industry experts are suggested to play their respective roles in quality assuring the translation work. Nevertheless, no research has yet tried to compare evaluation principles between student translators and professional translators, two important stakeholders in the translation learning process. In this paper, therefore, a qualitative method will be used to find out the thinking patterns between student translators and the professional trans-editor when evaluating translations, and attempts to provide illuminating examples to enrich this sub-field of Translation Studies.

\section{Research Design}

\subsection{Research Questions}

This paper sets out to answer the following key questions:

1) What are the differences in revision techniques between student translators and the trans-editor?

2) What are the common translation pitfalls summarised by student translators and by the trans-editor, respectively?

3) How can these findings improve translation quality and then enrich translation teaching?

\subsection{Research Methods}

\subsubsection{Initial Observation}

The initial thoughts of this study stem from the author's teaching of a Translation of Finance and Economics News module. This module runs two semesters for year 2 students at university level. Differing from traditional teaching with a textbook, this module works collaboratively with the iNews Portal (henceforth iNews) of China Daily(Note 1). INews is a crowdsourcing trans-editing platform. The student translators need to register as translators in the iNews website, and translate or trans-edit news reports on a regular basis. To be more precise, student translators translate finance and economics news articles under the supervision of the module convenor and the professional trans-editor from China Daily. Student translators normally work in groups, and they mainly translate English news articles into Chinese, sometimes vice versa. In the group translation processes, student translators are suggested to invite their fellow students to revise the group translation work before submitting to the iNews portal for final correction. After the whole translating and evaluating processes, the module convenor compares student translators' translation and revision with the professional trans-editor's versions. In this model, student translators, the trans-editor and the module convenor are the three stakeholders of this module, working very closely to accomplish each task. In addition to classroom teaching, student translators can apply to the follow-up online internship offered by iNews. The internship runs 4 cohorts a year, and each cohort lasts 2 months. The student translators are afforded an enormous opportunity to practise their trans-editing skills under the supervision of China Daily's in-house trans-editor teams.

Based on the large amount of translated texts, it has been found that student translators are easily affected by the source text, and their revisions are largely at word and sentence levels. They are less experienced in revising translations from the angle of readership and of pragmatic effect. In comparison, when observing the trans-editor's tracks and changes, the revised parts mainly bring translations in line with target readers' expectations and evaluations of a text. Therefore, this paper aims to explore student translators and the trans-editor's thought processes when evaluating the translation work of others. Further, through the comparison of student translators and professional trans-editors, both university lecturers and translation learners may be made aware of in which ways they can improve translation quality to better meet professional standards. With this in mind, in-depth interviews were carried out accordingly.

\subsubsection{In-depth Interview}

According to Yin (2014, p.113), interviews are an essential source of data, and well-informed interviews can provide researchers with insights into human affairs or actions. A particular benefit of interviews is that personal experience and opinions towards a specific subject can be directly accessed (Silverman, 2013). Further, as Jiang et al. (2010, p.158) points out, interviews offer free description to capture in-depth viewpoints. However, one possible risk of interviews might be too narrative in style which may affect the validity of the research results (Saldanha \& O'Brien, 2013, p.169). In this case, using structured/semi-structured interviews is an effective technique. Considering the research purposes in this study, in-depth interviews with open-ended questions was deemed an appropriate method, 
focusing on the "elicitation of perceptions, beliefs and motives" (Böser, 2016, p.236). Open-ended questions may leave enough space for student translators and the trans-editor to describe their individual experiences in evaluating the work of others which may in turn give the researcher a landscape of students' common pitfalls occurring during the translation process so as to reflect on teaching activities from a pedagogical perspective ( $\mathrm{Li}, 2013$, p.11). On the other hand, structured interviews guide both the interviewer and the interviewees logically avoiding going off topic or losing focus.

\subsection{Research Participants}

Nine student translators and the senior trans-editor from our industry partner were selected as interviewees to participate in this study. These interviewees' names have been replaced by letters (interviewee A to interviewee J) to ensure anonymity. These student translators worked both as the iNews interns to evaluate and revise texts translated by other students across China and as the decision makers in their own and their peers' group exercises. The senior trans-editor has participated in the whole teaching process of Translation of Finance and Economics News module and has plenty of experience in trans-editing English news. The profiles of these nine student translators and the trans-editor are presented in tables 1 and 2, which details their time engaged in the evaluation process and the number of texts they worked on as revisers.

Table 1. Profiles of Student Translators

\begin{tabular}{cccccc}
\hline Interviewee & Gender & $\begin{array}{c}\text { Translation } \\
\text { learning years }\end{array}$ & $\begin{array}{c}\text { Internship } \\
\text { period }\end{array}$ & $\begin{array}{c}\text { Number of } \\
\text { texts }\end{array}$ & $\begin{array}{c}\text { Length per } \\
\text { text }\end{array}$ \\
\hline A & F & 2 years & 2 months & 20 & 1000 words \\
B & $\mathrm{F}$ & 2 years & 2 months & 20 & 1000 words \\
C & M & 2 years & 4 months & 50 & 1000 words \\
D & F & 2 years & 2 months & 23 & 1000 words \\
E & $\mathrm{F}$ & 2 years & 2 months & 30 & 1000 words \\
F & F & 2 years & 2 months & 20 & 1000 words \\
G & F & 2 years & 2 months & 22 & 1000 words \\
H & F & 2 years & 2 months & 20 & 1000 words \\
I & F & 2 years & 2 months & 14 & 1000 words \\
\hline
\end{tabular}

Table 2. The Profile of the Trans-editor

\begin{tabular}{lllll}
\hline Interviewee & Gender & Years of revision & Number of texts & Length per text \\
\hline $\mathbf{J}$ & $\mathrm{M}$ & 15 years & Numerous & 1000 words \\
\hline
\end{tabular}

As shown in tables 1 and 2, the maximum number of translation texts revised by student translators is 50 , whilst the minimum number is 14 . On average, each student translator revised at least 24 news articles translated by their peers. Their experience of evaluation accumulated continuously. The senior trans-editor has considerable experience of evaluation and has quality assured the final versions of numerous translation work. Their points of view are taken into consideration in this study.

\subsection{Interview Questions}

The interview questions were divided into two parts targeting different groups of participants. One deals with student translators, and the other covers the trans-editor's points of view. With regard to student translators, interview questions were asked predominantly from four perspectives. The first part contains student translators' evaluation criteria. The second and third parts targeted mainly student translators' observations of translation pitfalls, and their reflections on the differences between their own revisions and the editor's final corrections. The final part deals with translation learning, aiming to figure out to what extent these evaluating experiences can improve student translators' translation quality and further improve their translation competences. The trans-editor is interviewed mainly from the perspective of evaluation criteria as well as common pitfalls in students' translations. 


\section{Comparing Evaluation Criteria between Student Translators and the Professional Trans-editor}

\subsection{Student Translators' Criteria for Evaluation}

It was noted in the conversations with student translators that their evaluation principles include the following aspects: (1) good understanding of the source text (ST), including words and sentences; (2) the terminology should be translated accurately; (3) the clumsy expressions used in the Chinese target text (TT) should be reduced; (4) logical relations in information in the target text should be dealt with carefully; (5) the translation style should be consistent with the original text; (6) register is important; (7) subject area knowledge needs to be rendered appropriately; and (8) meaning in the context should be taken into consideration.

More specifically, most of the interviewees pay equal attention to the understanding of the source text and the re-expression of the target text when evaluating the work of others. In terms of the source text, student translators stress the importance of excellent mastery of subject matter and the accurate transfer of the source text information. Of these, $60 \%$ of the student translators consider the complete comprehension of the whole source text, while the rest focus more on a command of vocabulary, terminology or sentences meanings.

The student translators offered more detailed criteria on the target text, namely the translation itself. After synthesising their descriptions, it was noted that: (1) accurate translation of terminology, (2) the logical relations between phrases, sentences, and paragraphs, and (3) reducing clumsy renderings were the most frequently mentioned aspects. Take terminology translation for example, interviewee A argues that " whether the financial and economic terms are carefully dealt with when translating finance and economics news is an important criterion”. This was echoed by several other student translators. In news translation, they also stated that proper names and cultural idiosyncrasies should also be translated accurately. In addition, Interviewee D explained "collocation patterns should be in relation to the target language systems." Then, there is the trap of over-translation, as mentioned by Interviewee $\mathrm{H}$, "several student translators use Chinese idioms in their translation in order to make their language expressions more elegant. However, the selected Chinese idioms might be different from the meanings in the English source text. In this case, the evaluator need to pay special attention to this misinterpreting and make changes accordingly”.

According to the student interviewees, phrases, sentences and paragraphs should be logically linked when rendered in the target text. This is also the consensus when they are evaluating their peers' translation. Specifically, interviewee B assesses "whether each sentence coheres with other parts of the text in a reasonable way". This perception resonates with Interviewee G, arguing that "the translations should connect together words and expressions to make the sentences coherent and to make sense to the target text readers". Interviewee F proposes more thoughts, explaining that:

......I would consider the inner logical relations within a sentence. For example, I would read the translated sentence to check out whether it is smooth. If not, I would make changes accordingly. Moreover, I would consider the inter logical relations between sentences. Translation problems such as repetitions and incoherent content need to be corrected by student revisers.

Their corresponding strategies towards logical issues include using cohesive devices and adopting the translation method of 'transposition' to undertake the structural change (Vinay \& Darbelnet, 1958). This is particularly obvious from the English into Chinese translation. In this way, the organisation of the texts translated and assessed by student translators "are connected to each other by virtue of lexical and grammatical dependencies" (Baker, 2011, p.231), which lies in the words that both writer and reader see.

Another important criterion adopted by student translators is the quality of translations. As far as the English into Chinese translation is concerned, most of them evaluate the Chinese renderings in order to avoid redundant information. For example, interviewee B described that she "condenses the length of the Chinese sentences and reduces repetitive expressions". Interviewee D holds a similar viewpoint, evaluating "whether the words, phrases and sentences are redundant or not, paying particular attention to the news headlines; the news headlines should be translated in a concise style".

\subsection{The Trans-editor's Criteria for Evaluation}

The trans-editor (interviewee J) summarises six major revising criteria in the process of evaluating and revising student translators' work. They are: (1) the translation should offer a complete rendering of the words, expressions and ideas of the source text; (2) the translation should be entirely appropriate to the style of a newspaper, and the terminologies in certain subject areas should be rendered accurately and professionally; (3) the translation should have logical links between paragraphs; (4) the style and manner of the writing should be localised within target culture conventions; (5) the translation should read like an original piece written in the target language; (6) the 
translation should maintain optimal relevance with the target text readers when necessary.

\subsection{Comparison of Evaluation Criteria between Student Translators and the Trans-editor}

The above evaluation philosophy was also reflected in the actual revising procedures of the student translators and the trans-editor. After synthesising both interview statements and revised sample texts, the major differences between student translators and the editor are summarised in table 3.

Table 3. Comparison of Revision Principles of Student Translators and the Trans-editor

\begin{tabular}{|c|c|c|}
\hline Parameter & Student translators & Trans-editor \\
\hline Relation to ST & - Loyal to the ST & $\begin{array}{l}\text { - Respect for the form of the } \\
\text { ST, but re-context the ST } \\
\text { into TT context }\end{array}$ \\
\hline The form of target language & $\begin{array}{l}\text { - Pay attention to details, such as } \\
\text { technical terms } \\
\text { - Consider logical relations } \\
\text { between sentences, more at the } \\
\text { textual level } \\
\text { Be aware of the redundant } \\
\text { information }\end{array}$ & $\begin{array}{l}\text { - Pay attention to key } \\
\text { information } \\
\text { Consider both coherence } \\
\text { and cohesion, more at the } \\
\text { pragmatic level } \\
\text { - Simpler and clearer } \\
\text { language }\end{array}$ \\
\hline Effect & $\begin{array}{l}\text { Translation awareness } \\
\text { Focusing on the whole } \\
\text { translating process }\end{array}$ & $\begin{array}{ll}\text { - } & \text { Professional awareness } \\
\text { - } & \text { More conventional within } \\
\text { news writing or } \\
\text { trans-editing }\end{array}$ \\
\hline
\end{tabular}

A stark contrast between student translators and the trans-editor is that student translators evaluate the "accuracy of the reproduction of the significance of the ST", while the trans-editor assesses the "accuracy of communication of the ST message in the TT” (Munday, 2016. p.72). This can be exemplified through the translation of news headlines. Due to the inverted pyramid structure of English news, the most important information is presented in the first paragraphs (Bielsa \& Bassnett, 2011, p.98), summarising the stance and the entire content. In this sense, the news headline "serves as the summary of the summary" (Cheng, 2011, p.219), using concise languages to interpret the most attractive information to news readers. Although this is a consensus in both English news headlines and Chinese headlines, they vary to a great extent in verb characteristics, sentence structure, the use of questions, and the depth and width of information (Biber \& Conrad, 2009). As Li (2017, p.12) explains, English news headlines focus more on one aspect of the story, which is called "accentuation". Chinese news headlines, however, tend to make a clean sweep of all the key information, which is called “totalism”. In translating English news headlines into Chinese, student translators prefer to stick closely to the English pattern, and revise more language expressions than content. The trans-editor, however, has a markedly different method, revising the headlines from the perspective of the whole text and conveying the intent of the source text. For example,

\section{ST headline:}

Amazon raises minimum wage for US and UK employees

TT by student translators:

亚马逊上调英美员工最低工资 [Amazon raises US and UK employees’ minimum wage]

TT by the student reviser:

亚马逊英美员工：最低工资上涨 [Amazon US and UK employees: minimum wage increasing]

TT by the trans-editor:

亚马逊在舆论压力之下上调英美员工最低工资 [Amazon, under the pressure of public opinion, raises minimum wage for US and UK employees]

Source: The Guardian 
In the original translation, student translators rendered the English headline into Chinese with full respect to the ST information, only transporting the order of the phrases without altering the meaning. The selected student translator, who is responsible for revising this piece of work, put "Amazon US and UK employees" as the subject, using a colon to explain what happened to these employees - that their minimum wage was increased. The student reviser only revised the Chinese expression, but kept the same meaning as the first version. The trans-editor, however, altered the ST headline, adding in the reasons for raising minimum wages for US and UK employees. Such added information is a generalization from the news report as a whole. The trans-editor's version, in some sense, is more conventional with the Chinese news reporting system.

As discussed previously, student translators do stress the importance of logical relations when organising the target texts. However, their habit of focusing on micro-level features of a text might prevent them from observing macro-level errors (Mossop, 2010, p.182). They evaluate to a great extent at the textual level (cohesion), namely "the network of relations which organise and create a text" (Baker, 2011, p.230), while paying less attention to the entire significance of a text (Colina, 2015, p.115). Moreover, in contrast to academic prose, in which abundant linking adverbials are employed to develop arguments and to establish cohesion (Biber \& Conrad, 2009, p.121), newspaper articles contain fewer conjunctions and the text cohesion can be attributed to various sources (e.g. organisation, other documents, eye witnesses, or experts in certain fields) (ibid, 2009, p. 122). In other words, the cohesion and coherence of newspaper articles is in many cases established implicitly rather than explicitly. This also puts a demand on readers' knowledge in perceiving the connection and also the translators' ability in reproducing the writer's intention in the target text.

With regard to the professional trans-editor, textual interference is not a major issue. He is more concerned with interpreting the underlying semantic relations of a text. In this context, the trans-editor's evaluation is more at the level of coherence, which is a far more pragmatic approach. According to Baker (2011, p.233), whether a text coheres or not (makes sense or not) depends on whether the reader can relate what he already knows with the knowledge presented in the text. In other words, the readers' specialty, educational background, previous experience of both linguistic phenomenon and extra-linguistic knowledge do "influence the coherence of a text in some degrees" (ibid., p.234). From the interviews as well as the sample texts, it can be seen that the professional trans-editor has taken target readers' cultural and intellectual background into account, and used coherence serving as a guideline to ensure accuracy in the message and logic in sense (Mossop, 2010).

Thirdly, the form of the target language is more concise in the trans-editor's revision. Highlighting the key points while removing secondary information is a method frequently used by the trans-editor. For instance, "Ali pay" and "WeChat pay"(Note 2), the top mobile payment services in China, might be mentioned in some English news articles regarding Chinese consumers' shopping habits or Chinese digital business. These two terms might be unfamiliar concepts to readers outside China. Therefore, English reporters opt to add an explanation to these terms. But for Chinese readers, both "Ali pay" and "WeChat pay" are the most frequently used payment methods in their daily life. In the Chinese translation, the trans-editor chooses to delete such extra explanations to avoid repetition. However, student translators, when they encounter similar cases, are often afraid of deleting them.

Finally, student translators may be less experienced in anticipating target readers' sociocultural knowledge (Colina, 2015), expectations, or subject area knowledge due to a lack of work experience and real world experience. This may affect their language choices in both translation and revision. For example, there are many words and expressions having multiple meanings in different contexts. In this sense, a word or phrase might be translated correctly but not appropriately in the specific subject area. The following example regarding a Chinese into English sentence translation may better illustrate this idea.

ST:

…...2018 年第一季度的学生留存率达到 $78.9 \% \ldots . . .$.

TT by student translators:

...... Student retention rate reached $78.9 \%$ in the first quarter of 2018.

TT by the student reviser:

...... Student retention rate reached 78.9\% in the first quarter of 2018.

TT by the trans-editor:

Student continued their enrolment at a rate of $78.9 \%$ in the first quarter of 2018. 
In theory, "retention rate” is the English equivalent to the Chinese phrase “留存率”, meaning the customer retention performance of a business organisation. This translation is in line with readers who have background in the education sector. However, this news article was originally a report published before a Chinese language training organization went public on the New York Stock Exchange. The amount of students who continued choosing the language courses offered by this company is an important criterion for stakeholders to consider. In this case, the trans-editor has changed the "retention rate" into "student continued their enrolment at a rate of $78.9 \%$...", which is more explicit and conventional in this text.

The above comparisons and analysis highlight that student translators and the trans-editor have adopted different approaches to translation quality assessment due to their roles and responsibilities. As for the translation of the ST by student translators, priority is given to the assurance of transferability into the target text (Koller, 1979; House, 2015), preferring linguistically-oriented approach to evaluate the translation (ibid., 2015) and reserving the flavour of the source text (Newmark,1981). Influenced by this concept, student translators spent numerous hours assessing lexical and grammatical mismatches and then revising individual words, phrases, grammatical uses or other linguistic units. In other words, their evaluation is the pursuit of perfection in the translation itself. As a result, some revised work can still be recognised as a 'translation' immediately instead of an original piece of writing.

The trans-editor, on behalf of his news agency, asserted his identity and articulated his power of discourse (Cheng, 2011, p.229) in the evaluation process. His approach is more response-based (House, 2015, p.10-11), stressing the importance of translation purpose, the function of the text, and readership. In this case, he has utilized his considerable trans-editing skills, and his revisions are generally more concise in content, more powerful in communication and more professional in tone. As a result, the revised translations, in many cases, can be directly used as news reports from a foreign source.

\subsection{Comparison of Translation Pitfalls Summarised by Student Translators and the Trans-editor}

The study of translation pitfalls is "a very useful task to correct both typical and atypical deviations in the learning situation" (Cabanas, 2012, p.1439), and the discussion of student translators' problems is a common practice in the classroom (Gile, 2004). In this study, all the participants have been asked to generalize student translators' translation problems in order to contribute further insights into translation teaching from the perspective of English-Chinese translation, a linguistically distant language pair. Table 4 presents the details.

Table 4. Translation Pitfalls Summarised by Student Translators and the Trans-editor

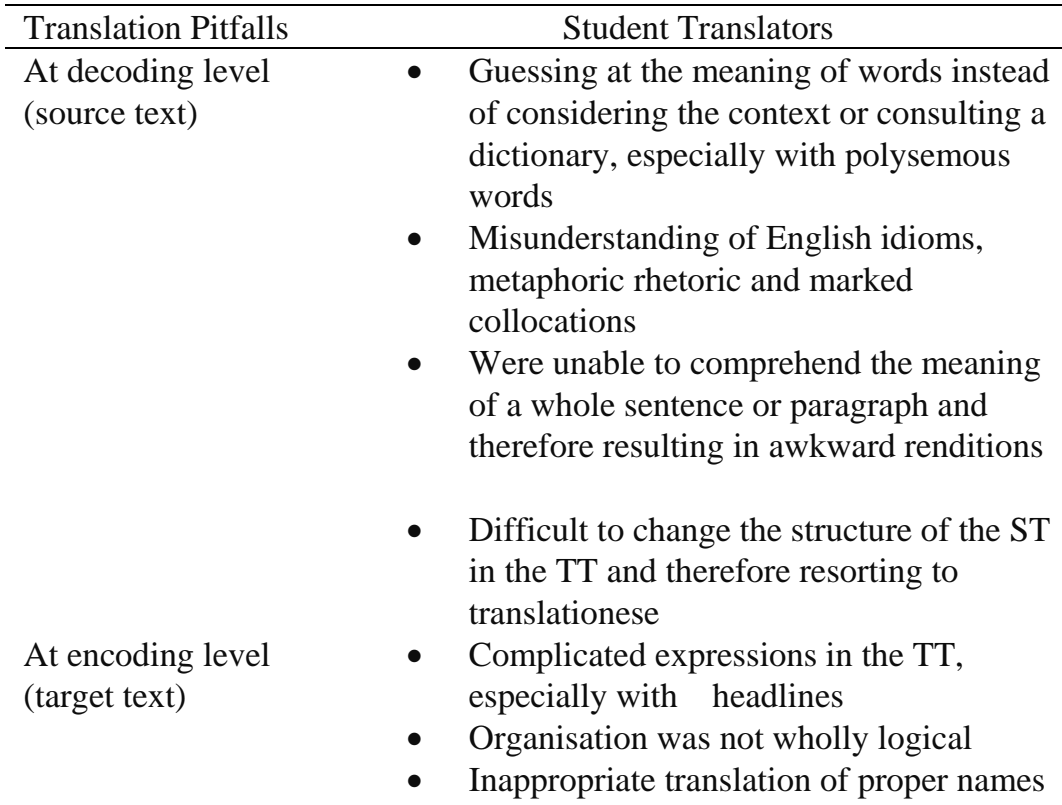

The Trans-editor

- Some words and sentences were misunderstood

- Inadequate understanding of the information within the context

- $\quad$ Not proficient at researching documents and subject area knowledge

- Inappropriate interpretation of certain terms and expressions

- $\quad$ Difficult to deal with Complex sentences or "Russian doll" sentences which contain additional layers of information

- Some renditions were not arranged coherently, or did not follow a logical sequence

- Expressions were not concise 
As viewed in table 4, the trans-editor and student translators share a few things in common. They summarise translation problems from both the comprehension of the source language and the output in the target language. They also believe that student translators may have misunderstandings of certain technical terms, especially when these terms have implied meanings. Some student translators may have a partial understanding of sentences and paragraphs but do not place them within the correct context. Further, both the trans-editor and student translators have observed that students are less likely to deal with complex sentences during the translating process. It is difficult for them to slice away long sentences into shorter ones, and then link those shorter sentences to produce semantically and syntactically sound translations. This is actually the biggest part for editorial changes. From a discourse perspective, student translators and the trans-editor are concerned with the overall organisation of students' translations. It can be also seen from table 4 that student translators place greater emphasis on translation pitfalls at and above word level, while the trans-editor pays more attention to the misunderstanding of translation content as well as misinterpretation of sentence structures.

In light of the above analysis, revising peer translators' work is an invaluable experience for student translators to develop the ability to evaluate and to justify decisions as well as comment on them (Kelly, 2005, p.143), which is an essential skill in the translation profession. Summarising common translation problems made by their fellow students benefits student translators by making them reflect on their own translating processes and to think out of the box. Receiving feedback from professional trans-editors outside of university also provides learners with opportunities to take professional criteria into account, and above all, to improve their translation quality.

\section{Conclusion and Implications}

This research set out to provide readers with qualitative and descriptive data on translation evaluation criteria. In view of the comparison of the student translators and the professional trans-editor, the translation evaluation criteria of these two groups differs in the following aspects: (1) different purpose and stance for evaluation. The professional trans-editor evaluates the work of translation from the perspective of target readers' needs and reading habits as well as newspaper writing conventions, while student translators place greater emphasis on a loyal renderings of the original news article; (2) different types of evaluation. The trans-editor tends to highlight key elements in a news story while "feeling free to clarify obscurities" (Munday, 2016, p.45). Student translators concentrate on details in the translating process such as lexical mismatches and syntactic mismatches; (3) different effects after evaluation. The trans-editor is more sensitive to the different linguistic conventions between the English and Chinese languages, and the revised translations read more like original news reports without altering the original meaning. Student translators, on the other hand, are more easily affected by the writing style and manner of the source text, and their revised works of translation can still be recognised as translations.

The different preferences and cognitions in translation evaluation between the professional trans-editor and student translators may have wider implications for translator trainers and learners. Through the comparison of student translators' peer evaluations and the trans-editor's final versions, the university lecturer can be made aware of students' progress and difficulties in learning, as well as the gap between their current level and market needs. From the perspective of translation learners, the generalization of common translation pitfalls made by their peers helps them to think about relative coping strategies to improve their translation quality. In addition, excellent translations encountered during the their evaluation process may also serve as invaluable learning resources. Furthermore, using this method, students are afforded an overall understanding of how the media industry works. With the prerequisite that most translation programmes aim to cultivate high-calibre professional translators, "it is rational to acknowledge what the professional standards are" (Hu, 2018, p.9) and then to decide what and how to embed these standards into classroom teaching.

Finally, the knowledge and expertise of one university can also be transferred to other institutions. This research has examined the different evaluation principles between student translators and the professional trans-editor in a Chinese context. Similar research can be designed and conducted in academic contexts in other regions of the world. English-Chinese translation practices can also be transferred to other language pairs. This can further enrich the field of translator training and translation practice.

\section{Acknowledgments}

The author wants to thank the two anonymous reviewers for their insightful comments, and thank Peter McSweeney for his constructive discussions about this study. 


\section{References}

Baker, M. (2011). In Other Words: A Coursebook on Translation. London and New York: Routledge. https://doi.org/10.4324/9780203832929

Biber, D., \& Conrad, S. (2009). Register, Genre and Style. Cambridge: Cambridge University Press. https://doi.org/10.1017/CBO9780511814358

Bielsa, E. \& Bassnett, S. (2011). Translation in Global News. Shanghai: Shanghai Foreign Language Education Press.

Böser, U. (2016). Interviews and focus groups. In C. V. Angelelli \& B. J. Baer (Eds.), Researching Translation and Interpreting (pp. 236-246). London and New York: Routledge.

Cabanas, J. M. O. (2012). Learning English as a Foreign Language: Translation and Error Analysis. US-China Foreign Languages, 10(8), 1431-1443.

Cheng, W. (2011). Innovative subjectivity of transeditors in intercultural communication-a case study of the translated news of the 2008 Olympic Games. Language and Intercultural Communication, 11(3), $215-231$. https://doi.org/10.1080/14708477.2010.549567

Colina, S. (2015). Fundamentals of Translation. Cambridge: Cambridge University Press. https://doi.org/10.1017/CBO9781139548854

Gile, G. (2004). Integrated Problem and Decision Reporting as a Translator Training Tool. The Journal of Specialised Translation, 2, 2-20.

House, J. (1977). A Model for Translation Quality Assessment. Tübingen: Narr.

House, J. (1997). Translation Quality Assessment: A Model Revisited. Tübingen: Narr.

House, J. (2015). Translation Quality Assessment: Past and Present. London and New York: Routledge.

Hu, W. (2018). Education, Translation and Global Market Pressures: Curriculum Design in China and the UK. Singapore: Springer Nature. https://doi.org/10.1007/978-981-10-8207-8

Jiang, X., Napoli, R. D., Borg, M., Maunder, R., Fry, H., \& Walsh, E. (2010). Becoming and being an academic: the perspectives of Chinese staff in two research-intensive UK universities. Studies in Higher Education, 35(2), 155-170. https://doi.org/10.1080/03075070902995213

Kelly, D. (2005). A Handbook for Translator Trainers. Manchester: St. Jerome Publishing.

Koller, W. (1979). Einführung in die Übersetzungswissenschaft. Heidelberg-Wiesbaden: Quelle und Meyer.

Li, D. (2012). Curriculum Design, Needs Assessment and Translation Pedagogy. Berlin: LAP LAMBERT Academic Publishing.

Li, D. (2013). Teaching Business Translation: A Task-based Approach. The Interpreter and Translator Trainer, 7(1), 1-26. https://doi.org/10.1080/13556509.2013.10798841

Li, D. (2017). News Translation: Principles and Methods (2nd ed.). Hong Kong: Hong Kong University Press.

Mossop, B. (2010). Revising and Editing for Translators. Manchester: St. Jerome.

Munday, J. (2016). Introducing Translation Studies: Theories and Applications (4th ed.). London and New York: Routledge. https://doi.org/10.4324/9781315691862

Newmark, P. (1981). Approaches to Translation. Oxford and New York: Pergamon.

Orlando, M. (2011). Evaluation of Translations in the Training of Professional Translators. The Interpreter and Translator Trainer, 5(2), 293-308. https://doi.org/10.1080/13556509.2011.10798822

Saldanha, G., \& O’Brien, S. (2013). Research Methodologies in Translation Studies. London and New York: Routledge.(Note 3)

Silverman, D. (2013). Doing Qualitative Research (4th ed.). London: SAGE Publications Ltd.

Vinay, J. P., \& Darbelnet, J. (1958). Stylistique comparée du français et de l'anglais: Méthode de traduction. Paris: Didier.

Yin, R.K. (2014). Case Study Research Design and Methods (5th ed.). CA: Sage. 


\section{Notes}

Note 1. China Daily is a national English-language newspaper in China, including both print media and digital media. A voice of China on the global stage.

Note 2. Ali pay is supported by Alibaba, a leading platform for global wholesale trade (https://www.alibaba.com/?spm=5386.1223793.a273ac.42.atANxm)

Wechat Pay is supported by Tencent, an internet-based technology and cultural enterprise (https://www.tencent.com/en-us/index.html) .They are the Chinese equivalents of Apple Pay. 